\title{
Rational design of selective metal catalysts for alcohol amination with ammonia
}

Tao Wang, ${ }^{a}$ Javier Ibañez, ${ }^{\mathrm{b}, \mathrm{d}}$ Kang Wang, ${ }^{\mathrm{b}}$ Lin Fang, ${ }^{\mathrm{b}}$ Maarten Sabbe, ${ }^{\mathrm{c}}$ Carine Michel, ${ }^{\mathrm{a}}$ Sébastien Paul, ${ }^{\mathrm{d}}$ Marc Pera-Titus, ${ }^{\mathrm{b},{ }^{*}}$ Philippe Sautet ${ }^{\text {ef, }}{ }^{*}$

a) Univ Lyon, ENS de Lyon, CNRS UMR 5182, Université Claude Bernard Lyon 1, Laboratoire de Chimie, F69342, Lyon, France.

b) Eco-Efficient Products and Processes Laboratory (E2P2L), UMI 3464 CNRS - Solvay, 3966 Jin Du Road, Xin Zhuang Ind. Zone, 201108 Shanghai, China.

c) Department of Chemical Engineering, Ghent University, Technologiepark 914, 9052, Zwijnaarde, Belgium.

d) Univ. Lille, Univ. Artois, CNRS, Centrale Lille, ENSCL, UMR 8181 - UCCS - Unité de Catalyse et Chimie du Solide, Lille, F-59000, France

e) Department of Chemical and Biomolecular Engineering, University of California, Los Angeles, Los Angeles, CA 90095, United States

f) Department of Chemistry and Biochemistry, University of California, Los Angeles, Los Angeles, CA 90095, United States

\begin{abstract}
The lack of selectivity for the direct amination of alcohols with ammonia, a modern and clean route for the synthesis of primary amines, is an unsolved challenge. Here, we combine first-principles calculations, scaling relations, kinetic simulations and catalysis experiments to unveil the key factors governing the activity and selectivity of metal catalysts for this reaction. We show that the loss of selectivity towards primary amines is linked to a surface-mediated C-N bond coupling between two $\mathrm{N}$-containing intermediates: $\mathrm{CH}_{3} \mathrm{NH}$ and $\mathrm{CH}_{2} \mathrm{NH}$. The barrier for this step is low enough to compete with the main surface hydrogenation reactions and can be used as a descriptor for selectivity. The combination of activity and selectivity maps using the $\mathrm{C}$ and $\mathrm{O}$ adsorption energies as descriptors is used for the computational screening of 348 dilute bimetallic catalysts. Among the best theoretical candidates, $\mathrm{Co}_{98.5} \mathrm{Ag}_{1.5}$ and $\mathrm{Co}_{98.5} \mathrm{Ru}_{1.5}$ (5 wt\% Co) are identified as the most promising catalysts from experiments.
\end{abstract}


Synthetic amines are major intermediates for the industrial production of pharmaceuticals, agrochemicals, bioactive compounds, polymers and dyes. ${ }^{1}$ In particular, primary amines are key reagents for derivatization reactions. Traditionally, amines are synthesized either from the direct reaction of ammonia with alkyl halides, or by reduction of nitro complexes and nitriles, ${ }^{2}$ generating harmful by-products, waste (e.g., salts) and using stoichiometric amounts of $\mathrm{H}_{2}$. Reductive amination of carbonyl compounds is another well-established methodology for the synthesis of primary aliphatic amines. Carbonyl reagents can also be generated in situ by the dehydrogenation of alcohols over $\mathrm{H}_{2}$-borrowing catalysts in the presence of amines and ammonia, favouring the generation of imine intermediates and providing the $\mathrm{H}$ atoms required for their conversion into amines. The direct amination of aliphatic alcohols with ammonia over heterogeneous catalysts is an already industrialized technology on a multi-thousand-ton scale. ${ }^{3}$ Furthermore, the amination of biomass-derived alcohols to higher order amines is envisioned as a promising route for a sustainable expansion of the amine chemistry, since water is generated as sole by-product and the process is compatible with biorefineries. ${ }^{4}$ Despite these benefits, industry still faces numerous challenges for amine production, most especially when regarding the synthesis of primary amines from alcohols. Ammonia is a poor amination reagent compared to the generated primary amine, resulting in a lack of selectivity as illustrated in Figure 1. Also, nitrile is a potential by-product that requires an additional pressure of $\mathrm{H}_{2}$ to be suppressed.

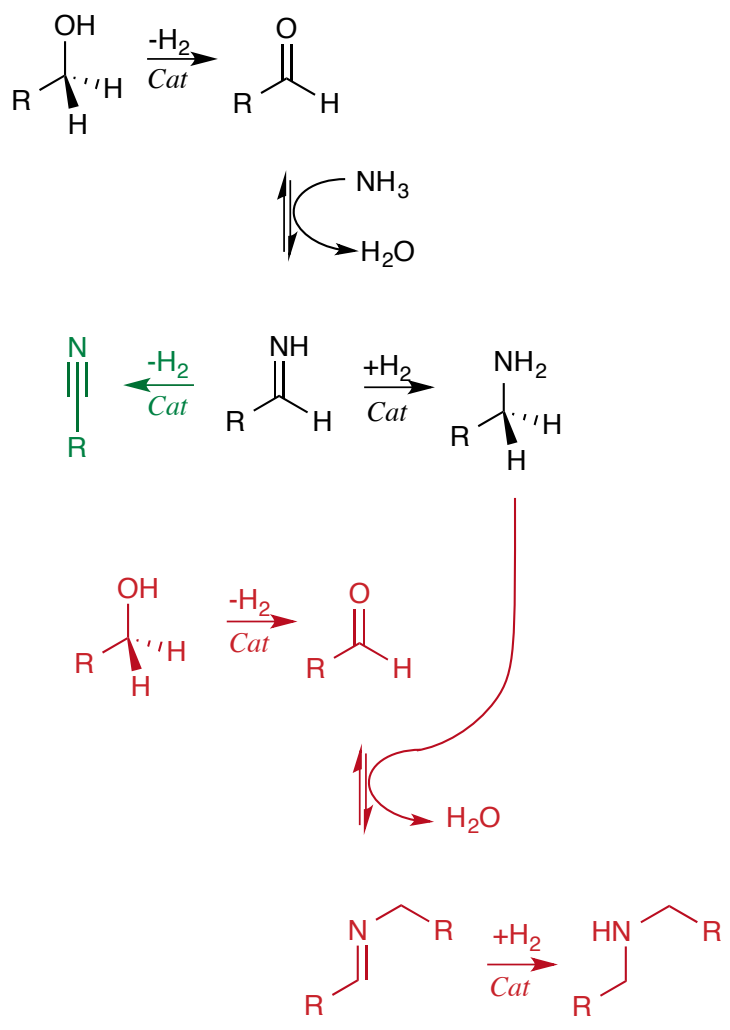

Figure 1. Reaction scheme for the catalytic amination of primary alcohols by ammonia. The scheme includes standard side reactions (dehydrogenation of the imine into nitrile, in green; primary alcohol amination by the primary amine, in red). Here we show that, in addition, a surface mediated C-N coupling plays a crucial role for the loss of selectivity in primary amine.

The most advanced $\mathrm{H}_{2}$-borrowing catalysts for the direct synthesis of amines from alcohols rely on homogeneous $\mathrm{Ru}$ and Ir complexes. ${ }^{5,6,7,8,9,10}$ In parallel, versatile heterogeneous catalysts based on transition metals have been developed, but they are only efficient on a specific scope of substrates. For example, noble metals such as Ru hydroxide, ${ }^{11}$ alumina- 
supported Ag clusters with Lewis acid co-catalyst, ${ }^{12}$ AgMo mixed oxides, ${ }^{13}$ Au nanoparticles over titania, ${ }^{14} \mathrm{Pt}-\mathrm{Sn}$ over $\gamma$ $\mathrm{Al}_{2} \mathrm{O}_{3},{ }^{15}$ and $\mathrm{Pd}$ nanoparticles supported over $\mathrm{Fe}_{2} \mathrm{O}_{3},{ }^{16} \mathrm{MgO}^{17}$ and entrapped in boehmite nanofibers, ${ }^{18}$ were reported to be active in the $\mathrm{N}$-alkylation of amines with aromatic alcohols. Moreover, noble-metal catalysts often suffer from poor activity for aliphatic substrates, low selectivity to monoalkylation and require promoters or co-catalysts. In contrast, nonnoble metal catalysts based on the Ni-Cu-Co triad ${ }^{19,20,21,22,23,24,25,26,27,28}$ and combinations thereof ${ }^{29,30,31}$ exhibit versatile activity and a variable degree of $\mathrm{N}$-substitution in the amination of aliphatic alcohols with ammonia at mild conditions and without additives. Despite these developments, the design of active and selective catalysts for the direct synthesis of polyamines from polyols is still an unsolved challenge.

To gain insight into the factors governing the activity and selectivity of metal catalysts, theoretical calculations have played a complementary (or even decisive) role in the last decade. ${ }^{32,33}$ However, as of today, no report is available on the relation between the nature of the catalyst and the activity/selectivity for the direct amination of alcohols, hence hampering rational catalyst design. Herein we present a joint theoretical and experimental study to unveil the key descriptors that control activity and selectivity for direct alcohol amination reactions using an $\mathrm{NH}_{3}$ source and a library of transition metals. Our approach relies on the construction of scaling relations for the binding energy of intermediates on the catalyst through $\mathrm{C}, \mathrm{N}$ or $\mathrm{O}$ atoms, combined with microkinetic modelling. The strategy emerging from this theoretical approach has been validated using tailor-designed experiments on a series of mono- and bimetallic catalysts using the amination reaction of 1-octanol with $\mathrm{NH}_{3}$ as a case example.

\section{Results}

DFT calculations using a model reaction. In a first step of our study, methanol $\left(\mathrm{CH}_{3} \mathrm{OH}\right)$ was used as a model aliphatic alcohol that was extended later to 1-octanol (see below). The reaction pathways were explored on compact surfaces for a library of nine transition metals (i.e. Co, $\mathrm{Rh}, \mathrm{Ir}, \mathrm{Ni}, \mathrm{Pd}, \mathrm{Pt}, \mathrm{Ru}, \mathrm{Re}, \mathrm{Os}$ ) for which the structural and energetic data are compiled in Supplementary Figures 3-11. At a typical $\mathrm{NH}_{3}$ pressure for amination experiments $(67.5 \mathrm{kPa})$, the surface was found to be not bare, but partially covered by $\mathrm{NH}_{3}$ (coverage of $1 / 9 \mathrm{ML}$ ), and the inclusion of chemisorbed $\mathrm{NH}_{3}$ was required to properly assess the relative activity of $\mathrm{Pd}$ and Ni catalysts. ${ }^{34}$ In light of this observation, co-adsorbed $\mathrm{NH}_{3}$ was hence considered in the remainder of this study for all possible pathways under the general $\mathrm{H}_{2}$-borrowing mechanism. Overall, this mechanism comprises three consecutive steps (Figure 2): ${ }^{5,6}$ (1) dehydrogenation of $\mathrm{CH}_{3} \mathrm{OH}$ to formaldehyde $\left(\mathrm{CH}_{2} \mathrm{O}\right)$; (2) reaction between $\mathrm{CH}_{2} \mathrm{O}$ and $\mathrm{NH}_{3}$ to generate methanimine $\left(\mathrm{CH}_{2} \mathrm{NH}\right)$ and water; and (3) hydrogenation of $\mathrm{CH}_{2} \mathrm{NH}$ to the final methylamine $\left(\mathrm{CH}_{3} \mathrm{NH}_{2}\right)$. The surface intermediates have been partially identified in the literature by combining dedicated kinetic measurements with isotope labelling experiments. ${ }^{35}$ The second reaction can be assumed to be at equilibrium with the gas phase on the guidance of recent experimental findings. ${ }^{36,37,38}$ 


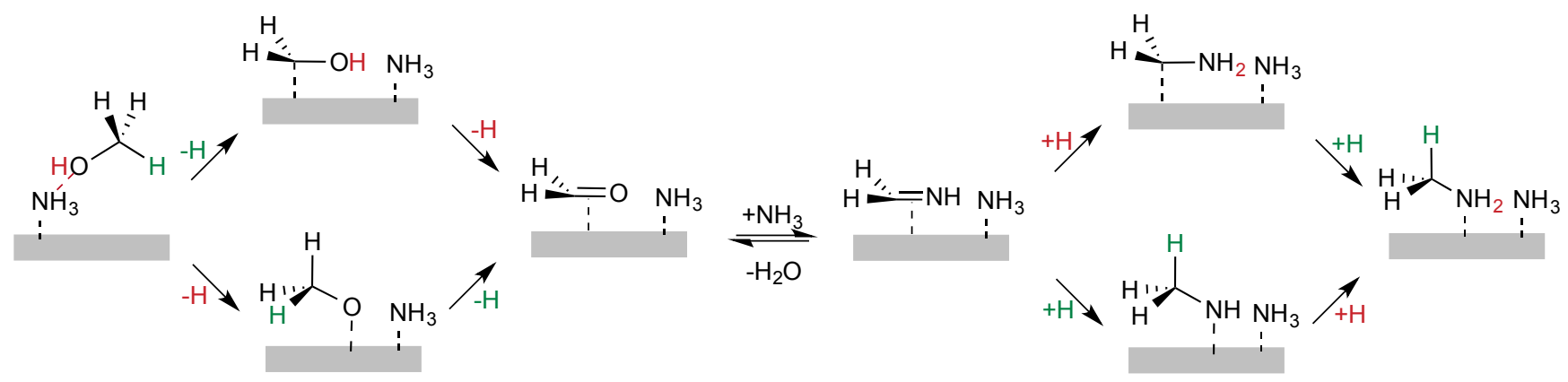

Figure 2. Main reaction pathways considered in the DFT calculation for methanol amination with $\mathrm{NH}_{3}$. The pathways include one co-adsorbed $\mathrm{NH}_{3}$ molecule and the metallic catalyst surface is represented by a grey rectangle.

After $\mathrm{CH}_{3} \mathrm{OH}$ adsorption driven by $\mathrm{H}$-bond formation with a co-adsorbed $\mathrm{NH}_{3}$ molecule, two pathways are a priori possible for the dehydrogenation step depending on whether one starts from $\mathrm{C}-\mathrm{H}$ or $\mathrm{O}-\mathrm{H}$ bond activation, forming $\mathrm{CH}_{2} \mathrm{OH}$ or $\mathrm{CH}_{3} \mathrm{O}$ as intermediates, respectively. After rapid formation of $\mathrm{CH}_{2} \mathrm{NH}$, the hydrogenation of the latter can similarly proceed via two analogous paths, forming $\mathrm{CH}_{2} \mathrm{NH}_{2}$ and $\mathrm{CH}_{3} \mathrm{NH}$ as intermediates.

Reduction of dimensionality using scaling and Brønsted-Evans-Polanyi relations. The energies of surface intermediates along the pathway are not independent and scaling relations can reduce the number of governing energy parameters to only 3 . Indeed, the adsorption energy of the intermediates presenting an unsaturation at the $\mathrm{C}$ atom (resp. $\mathrm{O}$ atom, $\mathrm{N}$ atom) can be linked by scaling relations to the adsorption energy of atomic $\mathrm{C}$ (resp. O, N). ${ }^{39,40}$ The number of independent parameters can be further reduced to 2 by noting that the $\mathrm{C}, \mathrm{N}$ and $\mathrm{O}$ adsorption energies follow an approximate but low-error linear relation (Supplementary Figure 12). This is explained by the fact that adsorption energy of a species is linked to the energy of its highest occupied molecular orbital (HOMO), and that $\mathrm{N}$ being of intermediate electronegativity, its $\mathrm{HOMO}$ energy can be expressed as a linear combination of that of $\mathrm{C}$ and $\mathrm{O}$. Hence, our energy space will be ascribed to $\mathrm{C}$ and $\mathrm{O}$ adsorption energies as independent energy descriptors, these being used to relate the intermediate energies.

In addition to the energy of the different intermediates, transition state energies play a key role on the reaction kinetics. Linear relations linking the activation energy of a given elementary step with its reaction energy have large applications. In heterogeneous catalysis, a prototype is the Brønsted-Evans-Polanyi (BEP) relation, connecting the kinetics and thermodynamics of a given elementary step. ${ }^{41,42,43}$ BEP or other relations can be applied to build kinetic models with limited DFT calculations. ${ }^{44,45}$ In our case, BEP relations were used to connect the elementary step energy barrier to the reaction energy of the different intermediates, these energies being linked to $C$ and $O$ adsorption energy descriptors as pointed out above (Supplementary Table 1). Errors in these relations are lower than $0.15 \mathrm{eV}$, which provides a good basis for further microkinetic modelling. The different energies characterizing the energy profile of the reaction network and the rate or turnover frequency (TOF) of the reaction can then be expressed as a sole function of two energy descriptors, abridging the screening of active catalysts for amination reactions. ${ }^{46}$

The energy of the intermediates and transition states were integrated into an explicit microkinetic model using the set of reactions listed in Table 1. In this approach, the dehydrogenation and hydrogenation steps were modelled as a HoriutiPolanyi elimination/addition of single hydrogen atoms. The reaction of $\mathrm{CH}_{2} \mathrm{O}$ with $\mathrm{NH}_{3}$, being assumed at equilibrium, was modelled using an Eley-Rideal mechanism where $\mathrm{CH}_{2} \mathrm{O}$ and $\mathrm{CH}_{2} \mathrm{NH}$ are adsorbed on the metal surface and $\mathrm{NH}_{3}$ and $\mathrm{H}_{2} \mathrm{O}$ 
react from the gas phase (Table 1, column 2). Alternative hypotheses for this step do not change the results (see details in Supplementary Computational details and Supplementary Tables 2 and 3 ).

Table 1. Reaction mechanism for $\mathrm{CH}_{3} \mathrm{OH}$ amination with $\mathrm{NH}_{3}$

\begin{tabular}{lcl}
\hline 1: $\mathrm{CH}_{3} \mathrm{OH}$ dehydrogenation & 2: $\mathrm{CH}_{2} \mathrm{O}+\mathrm{NH}_{3}$ to $\mathrm{CH}_{2} \mathbf{N H}+\mathrm{H}_{2} \mathrm{O}$ & 3: $\mathrm{CH}_{2} \mathrm{NH}_{\text {hydrogenation }}$ \\
\hline $\mathrm{CH}_{3} \mathrm{OH}(\mathrm{g})+2^{*} \leftrightarrow \mathrm{CH}_{3} \mathrm{OH}^{*}+{ }^{*}$ & $\mathrm{CH}_{2} \mathrm{O}^{*}+\mathrm{NH}_{3}(\mathrm{~g}) \leftrightarrow \mathrm{CH}_{2} \mathrm{NH}^{*}+\mathrm{H}_{2} \mathrm{O}(\mathrm{g})$ & $\mathrm{CH}_{2} \mathrm{NH}^{*}+\mathrm{H}^{*} \leftrightarrow \mathrm{CH}_{3} \mathrm{NH}^{*}+{ }^{*}$ \\
$\mathrm{CH}_{3} \mathrm{OH}^{*}+{ }^{*} \leftrightarrow \mathrm{CH}_{3} \mathrm{O}^{*}+\mathrm{H}^{*}$ & $\mathrm{NH}_{3}(\mathrm{~g})+{ }^{*} \leftrightarrow \mathrm{NH}_{3}{ }^{*}$ & $\mathrm{CH}_{2} \mathrm{NH}^{*}+\mathrm{H}^{*} \leftrightarrow \mathrm{CH}_{2} \mathrm{NH}_{2}{ }^{*}+^{*}$ \\
$\mathrm{CH}_{3} \mathrm{OH}^{*}+{ }^{*} \leftrightarrow \mathrm{CH}_{2} \mathrm{OH}^{*}+\mathrm{H}^{*}$ & $\mathrm{H}_{2} \mathrm{O}(\mathrm{g})+{ }^{*} \leftrightarrow \mathrm{H}_{2} \mathrm{O}^{*}$ & $\mathrm{CH}_{3} \mathrm{NH}^{*}+\mathrm{H}^{*} \leftrightarrow \mathrm{CH}_{3} \mathrm{NH}_{2}{ }^{*}+{ }^{*}$ \\
$\mathrm{CH}_{3} \mathrm{O}^{*}+{ }^{*} \leftrightarrow \mathrm{CH}_{2} \mathrm{O}^{*}+\mathrm{H}^{*}$ & & $\mathrm{CH}_{2} \mathrm{NH}_{2}{ }^{*}+\mathrm{H}^{*} \leftrightarrow \mathrm{CH}_{3} \mathrm{NH}_{2}{ }^{*}{ }^{*}$ \\
$\mathrm{CH}_{2} \mathrm{OH}^{*}+{ }^{*} \leftrightarrow \mathrm{CH}_{2} \mathrm{O}^{*}+\mathrm{H}^{*}$ & & $\mathrm{CH}_{3} \mathrm{NH}_{2}{ }^{*} \leftrightarrow \mathrm{CH}_{3} \mathrm{NH}_{2}(\mathrm{~g})+{ }^{*}$ \\
$2 \mathrm{H}^{*} \leftrightarrow \mathrm{H}_{2}(\mathrm{~g})+2^{*}$ & & \\
\hline
\end{tabular}

Note: $(g)$ : gas phase, *: active site corresponding to a surface with a pre-adsorbed $\mathrm{NH}_{3}$

Microkinetic simulation of activity and selectivity. On the basis of the energies issued from the BEP scaling relations and of the Eley-Rideal mechanism for the fast step from $\mathrm{CH}_{2} \mathrm{O}$ to $\mathrm{CH}_{2} \mathrm{NH}$, an activity map for amination (or equivalently TOF for alcohol conversion) could be generated as a function of the $\mathrm{C}$ and $\mathrm{O}$ adsorption energies at representative reaction conditions of amination reactions $\left(453 \mathrm{~K} ; 101 \mathrm{kPa}, \mathrm{p}_{\mathrm{CH} 3 \mathrm{OH}}=2.7 \mathrm{kPa}, \mathrm{p}_{\mathrm{H} 2}=36 \mathrm{kPa}\right.$ and $\mathrm{p}_{\mathrm{NH} 3}=24 \mathrm{kPa}$, Figure $\left.3 a\right)$. A TOF map with broader boundaries is provided in Supplementary Figure 13. Noteworthy, this map does not exhibit a simple volcano trend: it displays not only a maximum at low $\mathrm{O}$ adsorption energy (top left of Figure 3a), but also a ridge of high activity for an $\mathrm{O}$ adsorption energy of $\sim-5.9 \mathrm{eV}$. The map presents multiple maxima since both alcohol dehydrogenation and imine hydrogenation can follow two alternative pathways (Figure 2), and the optimum reaction path depends on the $\mathrm{C}$ and $\mathrm{O}$ adsorption energy parameter values. In the following lines, the reader will observe that, even if it does not correspond to the absolute highest activity on the map, this ridge presents good credentials for the design of amination catalysts. Experiments for 1-octanol amination with $\mathrm{NH}_{3}$ revealed a high TOF for amine formation for $\mathrm{Ni}^{\left(0.03 \mathrm{~s}^{-}\right.}$ $\left.{ }^{1}\right)$ and $\mathrm{Co}\left(0.04 \mathrm{~s}^{-1}\right)$ and a pronounced decline for both $\mathrm{Pd}\left(4.2 \times 10^{-3} \mathrm{~s}^{-1}\right)$ and $\mathrm{Ru}\left(9.7 \times 10^{-4} \mathrm{~s}^{-1}\right)$ (Supplementary Table 4 entries 2, 4, 10, 13; Supplementary Figure 14). The simulations, placing Ni and Co on the active ridge with a decrease on either side when moving to $\mathrm{Pd}$ or $\mathrm{Ru}$, are in good agreement with the measured TOFs. Pt $\left(0.010 \mathrm{~s}^{-1}\right)$ (Supplementary Table 4 entry 12; Supplementary Figure 14) exhibit an activity $\sim 3$ times smaller than that of $\mathrm{Ni}$ and Co, while the computed values place $\mathrm{Pt}$ at the same level. This slight discrepancy might point to a reduced Pt activity from poisoning during the amination experiments. As a matter of fact, thermogravimetric analysis on the spent $\mathrm{Ni}$, Co, Pd and Pt catalysts revealed that coke was formed in all the catalysts during the reaction even if a high $\mathrm{H}_{2}$ pressure was used (see Methods), but to a larger extent in the case of Pt. In light of this observation, we can attribute the decrease in activity for Pt compared to the computed value to coke formation (Supplementary Table 5). A degree of rate control analysis shows that the ratedetermining step for the reaction depends on the position on the map $\left(\mathrm{O}-\mathrm{H}\right.$ bond breaking in $\mathrm{CH}_{3} \mathrm{OH}$ for Os, $\mathrm{Ru} \mathrm{C}-\mathrm{H}$ bond breaking in $\mathrm{CH}_{3} \mathrm{OH}$ for $\mathrm{Pt}$, Ir, $\mathrm{Pd}, \mathrm{Rh}$ and $\mathrm{Ni}, \mathrm{N}-\mathrm{H}$ bond formation from $\mathrm{CH}_{2} \mathrm{NH}$ to $\mathrm{CH}_{2} \mathrm{NH}_{2}$ for Co and $\mathrm{C}$ - $\mathrm{H}$ bond formation from $\mathrm{CH}_{2} \mathrm{NH}_{2}$ to $\mathrm{CH}_{3} \mathrm{NH}_{2}$ for $\mathrm{Re}$, see Supplementary Figure 15).

In addition to the catalytic activity, the selectivity towards a given amine (in our case primary) is also a key target for amination. Our reaction network (Table 1), even if presenting already a large number of intermediates, does not account for side reactions being responsible for a loss of selectivity due to the formation of secondary and tertiary amines. As shown in Figure 1, one route for further alkylation of the amine comes from the possible coupling of the primary amine 
with the aldehyde generating a secondary imine. This coupling is often proposed to occur in the homogeneous phase. ${ }^{37,38}$ However, the observed selectivity is clearly metal-dependent, ${ }^{19}$ which suggests that a surface reaction step is also at play for the selectivity loss. A first possibility is the $\mathrm{C}-\mathrm{N}$ coupling between the hydroxymethyl $\mathrm{CH}_{2} \mathrm{OH}$ and the aminyl $\mathrm{CH}_{3} \mathrm{NH}$ intermediates into the aminoalcohol $\mathrm{CH}_{3} \mathrm{NHCH}_{2} \mathrm{OH}$. However, from the calculated maps of intermediate coverage from the kinetic simulations (Supplementary Figure 16) it is rather unlikely to find a metal catalyst that stabilizes both intermediates, hampering this pathway. Moreover, the corresponding product has never been detected experimentally so far. Another pathway for surface-mediated higher amine formation is the $\mathrm{C}-\mathrm{N}$ coupling between different $\mathrm{N}$-containing intermediates. ${ }^{35,47}$ Our kinetic modelling shows that the aminyl intermediate $\mathrm{CH}_{3} \mathrm{NH}$ and the imine $\mathrm{CH}_{2} \mathrm{NH}$ are the most abundant $\mathrm{N}$-containing intermediates on most catalyst surfaces and that the presence of other species such as aminoalkyl $\mathrm{CH}_{2} \mathrm{NH}_{2}$ or the amine $\mathrm{CH}_{3} \mathrm{NH}_{2}$ is rather unlikely (Supplementary Figure 16). Hence, the energy barriers were calculated on the above stated nine transition metal surfaces for four $\mathrm{C}-\mathrm{N}$ coupling reactions, i.e. $\mathrm{CH}_{3} \mathrm{NH} / \mathrm{CH}_{2} \mathrm{NH}$, $\mathrm{CH}_{3} \mathrm{NH} / \mathrm{CH}_{2} \mathrm{NH}_{2}, \mathrm{CH}_{2} \mathrm{NH} / \mathrm{CH}_{2} \mathrm{NH}$, and $\mathrm{CH}_{2} \mathrm{NH} / \mathrm{CH}_{2} \mathrm{NH}_{2}$ (Figure 4 and Supplementary Table 6-9). Transition states structures on $\mathrm{Co}(111)$ are shown in Figure 5, and similar geometries were found on other metals (Supplementary Figure 17). 

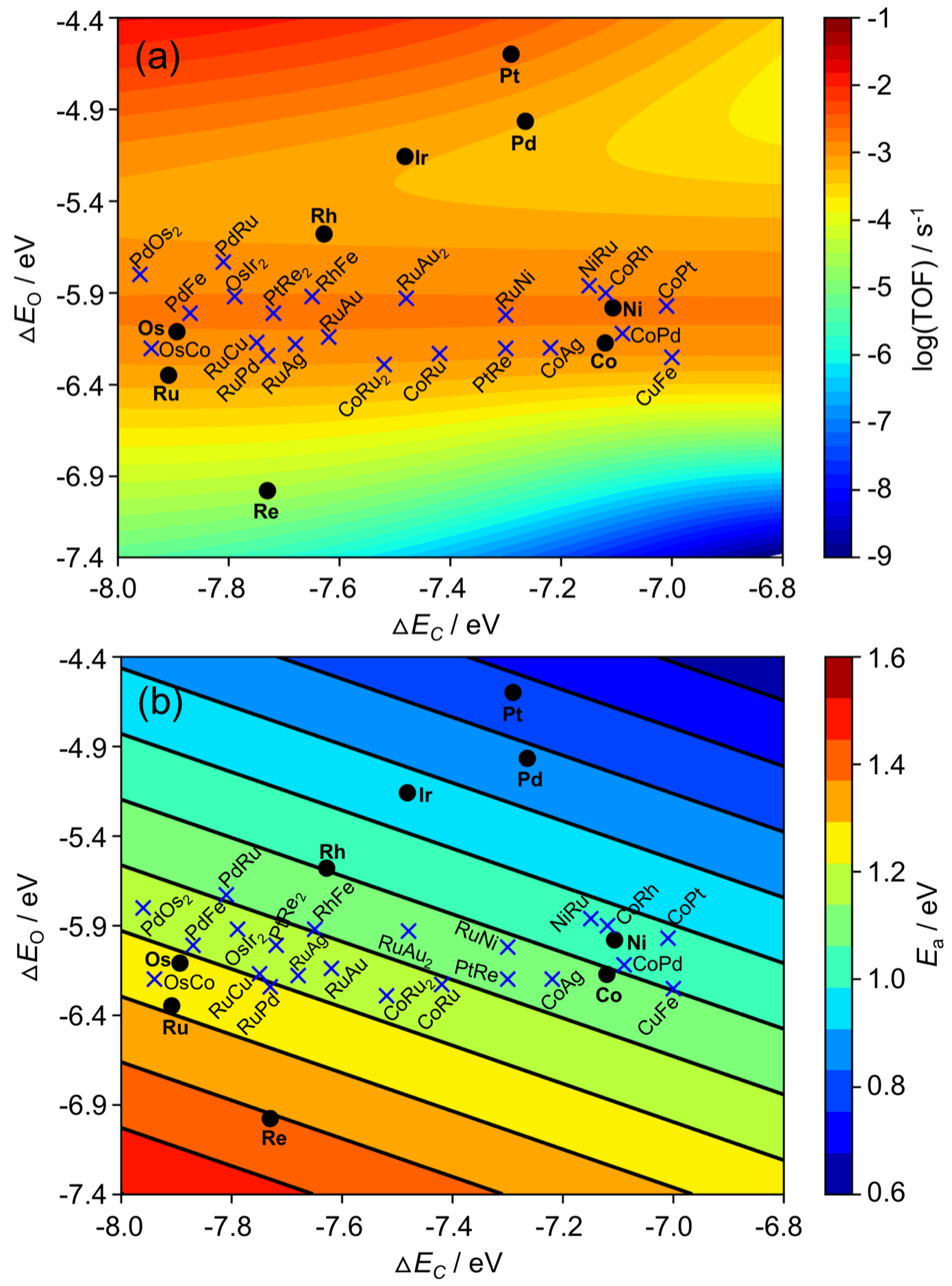

Figure 3: Calculated maps for activity and selectivity controlling barrier. (a) Calculated activity (TOF) map for direct $\mathrm{CH}_{3} \mathrm{OH}$ amination with $\mathrm{NH}_{3}$, and (b) Energy barrier for $\mathrm{C}-\mathrm{N}$ coupling between $\mathrm{CH}_{3} \mathrm{NH}$ and $\mathrm{CH}_{2} \mathrm{NH}$ at the catalyst surface conditioning the selectivity to the primary amine as a function of two energy descriptors, the adsorption energy of $C\left(\Delta E_{C}\right)$ and $O\left(\Delta E_{O}\right)$. Pure metal catalysts are indicated on both maps with full black dots. Dilute alloys candidates with potential high activity and high selectivity from the computational screening are indicated by blue crosses. $A B$ and $A B_{2}$ systems are rich in $A$ and dilute in $B$ and consist of a single $B$ metal atom or $B_{2}$ dimer embedded in a $(3 \times 3)$ surface of $A$, hence with a surface $B$ content of 0.11 or $0.22 \mathrm{ML}$, respectively. Conditions for kinetic simulations: $453 \mathrm{~K}, 101 \mathrm{kPa}, \mathrm{p}_{\mathrm{CH} 3 \mathrm{OH}}=2.7 \mathrm{kPa}, \mathrm{p}_{\mathrm{H} 2}$ $=36 \mathrm{kPa}$ and $\mathrm{p}_{\mathrm{NH} 3}=24 \mathrm{kPa}$. 


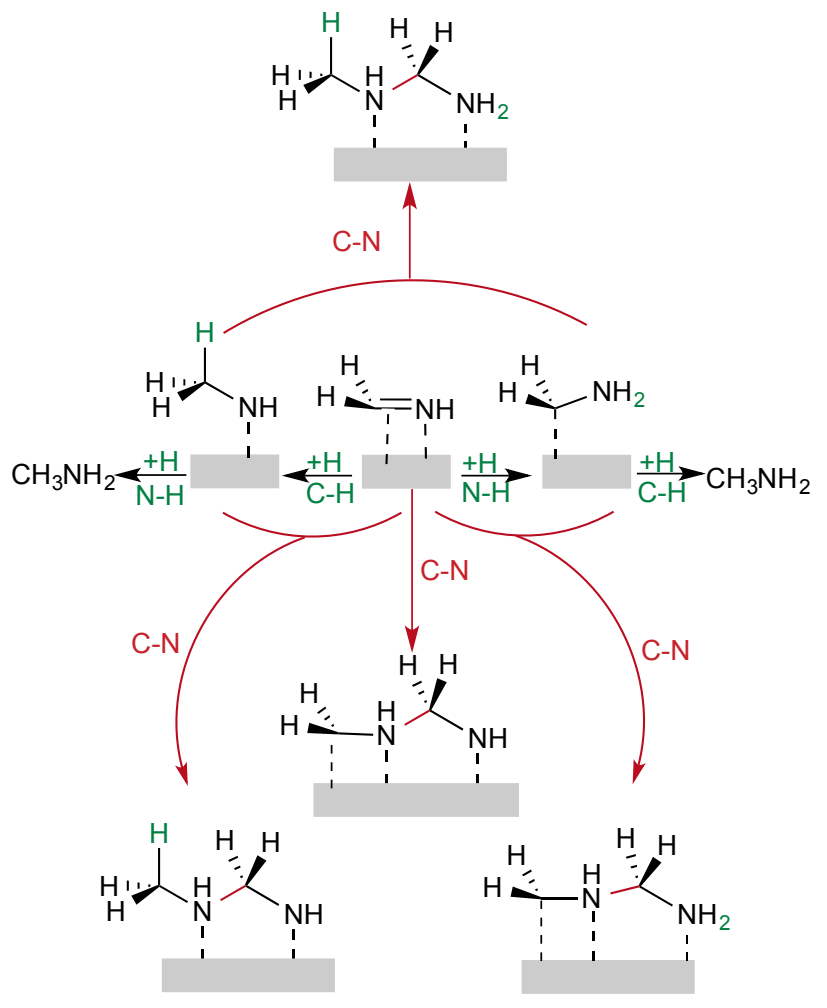

Figure 4. Four possible C-N coupling pathways catalysed by the metal surface. The pathways are based on the most likely surface intermediates on pure transition metals. The metallic catalyst surface is represented by a grey rectangle.

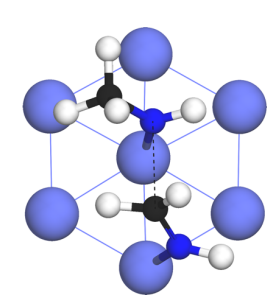

(a)

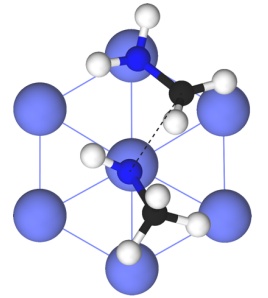

(b)

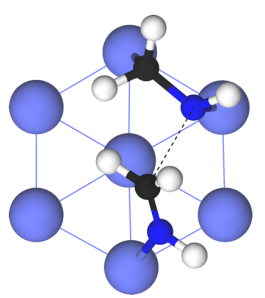

(c)

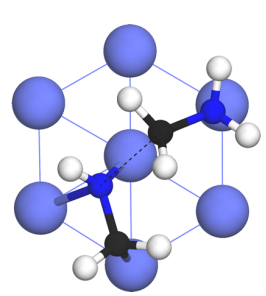

(d)

Figure 5. Transition state structures of $\mathrm{C}-\mathrm{N}$ coupling between various $\mathrm{N}$-containing intermediates on $\mathrm{Co}(111)$ surface. a, $\mathrm{CH}_{3} \mathrm{NH} / \mathrm{CH}_{2} \mathrm{NH}$. b, $\mathrm{CH}_{3} \mathrm{NH} / \mathrm{CH}_{2} \mathrm{NH}_{2}$. c, $\mathrm{CH}_{2} \mathrm{NH} / \mathrm{CH}_{2} \mathrm{NH}$. d, $\mathrm{CH}_{2} \mathrm{NH} / \mathrm{CH}_{2} \mathrm{NH}_{2}$.

For the $\mathrm{CH}_{3} \mathrm{NH} / \mathrm{CH}_{2} \mathrm{NH}_{2}$ coupling (Figure $5 \mathrm{~b}$ ), the energy barriers are higher than $2 \mathrm{eV}$ for the different metals. Hence, this $\mathrm{C}-\mathrm{N}$ coupling is unlikely. The $\mathrm{CH}_{2} \mathrm{NH} / \mathrm{CH}_{2} \mathrm{NH}$ or $\mathrm{CH}_{2} \mathrm{NH} / \mathrm{CH}_{2} \mathrm{NH}_{2}$ couplings (Figure $5 \mathrm{c}$, d) display lower barriers, but are still in most cases higher than those obtained for the hydrogenation steps. The easiest C-N coupling is $\mathrm{CH}_{3} \mathrm{NH} / \mathrm{CH}_{2} \mathrm{NH}$ (Figure 5a) for all metals except $\mathrm{Ni}$, for which the $\mathrm{CH}_{2} \mathrm{NH} / \mathrm{CH}_{2} \mathrm{NH}$ path is slightly less activated. Among the different metals, $\mathrm{Pt}$ and $\mathrm{Pd}$ were found to favour the most $\mathrm{C}-\mathrm{N}$ coupling reactions with barriers as low as $0.66 \mathrm{eV}$ and $0.74 \mathrm{eV}$, respectively, which are lower than the $\mathrm{C}-\mathrm{H}$ or $\mathrm{N}-\mathrm{H}$ formation barriers. The product of this coupling (i.e. $\mathrm{CH}_{3} \mathrm{NHCH}_{2} \mathrm{NH}$ ) leads to the secondary amine by hydrogenation and further $\mathrm{C}-\mathrm{N}$ bond cleavage. Since $\mathrm{CH}_{3} \mathrm{NH}$ and $\mathrm{CH}_{2} \mathrm{NH}$ also display the highest coverage on the different metal surfaces according to our kinetic simulations, the energy barrier for $\mathrm{CH}_{3} \mathrm{NH} / \mathrm{CH}_{2} \mathrm{NH}$ 
coupling can be used as a descriptor of the selectivity towards the primary amine: the lower the barrier, the less selective the catalytic process is foreseen. This barrier nicely scales with the $\mathrm{N}$ adsorption energy for the different metals (Supplementary Figure 18), namely the stronger the $\mathrm{N}$ adsorption energy (in absolute value), the higher the barrier, since a $\mathrm{N}$-surface bond needs to be broken during the reaction. The activation energy for $\mathrm{C}-\mathrm{N}$ coupling was hence represented by a simple function linking $\Delta \mathrm{E}_{\mathrm{C}}$ and $\Delta \mathrm{E}_{\mathrm{O}}$ as illustrated in Figure $3 \mathrm{~b}$, providing a direct indication of selective (high activation energy, i.e. low $\Delta \mathrm{E}_{\mathrm{C}}$ and $\Delta \mathrm{E}_{\mathrm{O}}$ ) and non-selective regions (low activation energy, i.e. high $\Delta \mathrm{E}_{\mathrm{C}}$ and $\Delta \mathrm{E}_{\mathrm{O}}$ ) in the maps. In agreement with the experimental results for 1-octanol amination with $\mathrm{NH}_{3}$, also matching reported results, ${ }^{15,19} \mathrm{Pt}$ on top of the map exhibits a high activity for amination, but a limited selectivity towards the primary amine ( $76 \%$ selectivity to octylamine in our experiment, Supplementary Table 4), since surface C-N coupling leading to secondary amines competes with imine hydrogenation. $\mathrm{Pd}$ and $\mathrm{Ir}$ are also placed in an unfavourable region of Figure $3 \mathrm{~b}$, in agreement with experiments. ${ }^{19}$ In contrast, the ridge of high activity in the middle of the map can provide more selective catalysts, which is the case of Co (90\% exp) or Ru (88\% exp). Ni gives a limited selectivity to primary amine (60\%), despite its favourable position in the map. For $\mathrm{Ni}$ an alternative $\mathrm{C}-\mathrm{N}$ coupling reaction $\left(\mathrm{CH}_{2} \mathrm{NH}+\mathrm{CH}_{2} \mathrm{NH}\right)$ provides a lower barrier, so that the simplified map of Figure $3 \mathrm{~b}$ overestimates its selectivity. Overall, the two maps plotted in Figure 3 provide guidelines for screening potential active and selective metallic catalysts for the direct amination of alcohols.

Predicting active and selective bimetallic catalysts. The descriptors presented above for monometallic catalysts were further used for designing bimetallic catalysts for amination. We performed extensive computations of $\mathrm{C}$ and $\mathrm{O}$ adsorption energies on 348 different alloys by combining the transition metals in the periodic table. Dilute alloys of $B$ in $A$ (noted $A B_{n}$ ) were modelled by substituting one $(n=1)$ or two neighbouring $(n=2) A$ atoms on a $p(3 \times 3)$ supercell by metal $B$, resulting in a coverage of $B$ of 0.11 or $0.22 \mathrm{ML}$ respectively. This screening identified 76 bimetallic alloys in the favourable window ($8.0 \mathrm{eV}<\Delta \mathrm{E}_{\mathrm{C}}<-6.8 \mathrm{eV}$ and $-6.4 \mathrm{eV}<\Delta \mathrm{E}_{\mathrm{O}}<-5.4 \mathrm{eV}$ ), where high activity and selectivity can be expected (Supplementary Table 10). Some examples are shown in Figure 3 marked with blue crosses. Nine alloy catalysts in three sub-families were chosen for experimental validation using the direct amination reaction of 1-octanol with $\mathrm{NH}_{3}$. Doping was performed by co-impregnation of the two metal precursor solutions over alumina with a surface dopant concentration affording 1.5 atom\% on the final catalyst. High Resolution - Transmission Electron Microscopy (HR-TEM) confirms the optimal metal dispersion for the different catalysts (Supplementary Figure 19), whereas Scanning Transmission Electron MicroscopyEnergy Dispersive Spectroscopy-Silicon Drift Detector (STEM-EDS-SDD) shows an intimate interaction between both metals at the level of spatial resolution of the cartographies (Supplementary Figure 20 and 21). Details for TOF, selectivity and yield to $\mathrm{N}$-products for the different catalysts are listed in Supplementary Table 4 . We believe the other predicted bimetallic catalysts in Supplementary Table 10 can trigger further experimental interests and efforts in developing catalysts for alcohol selective amination reactions.

The first family explores the alloy configuration locally around Co by building dilute alloys of $\mathrm{Ru}, \mathrm{Ag}, \mathrm{Pd}$ and $\mathrm{Pt}$ in $\mathrm{Co}$. Our motivation was to devise a strategy to enhance the Co activity while maintaining (or even improving) the selectivity towards primary amines. Co locates just below the high activity ridge (Figure 3a), and by doping with $\mathrm{Pd}$ and $\mathrm{Pt}$, the $\mathrm{O}$ adsorption energy decreases (in absolute value), shifting the $\mathrm{CoM}_{\mathrm{X}}$ catalyst towards the most active part of the ridge. This effect is however small, about a factor of two at the maximum, since Co is already not far from the ridge. This observation is attributed to the lower oxophilic character of $\mathrm{Pd}$ and $\mathrm{Pt}$ compared to Co. Turning now our attention into the selectivity map, the shift of the $\mathrm{O}$ and $\mathrm{C}$ adsorption energy to lower absolute values brings CoPt and CoPd dilute bimetallic catalysts to a region of lower $\mathrm{C}-\mathrm{N}$ coupling barrier between $\mathrm{CH}_{3} \mathrm{NH}$ and $\mathrm{CH}_{2} \mathrm{NH}$, suggesting a decrease of the selectivity towards 
the primary amine. In contrast, in the case of Ru or Ag doping, a radically different perturbation is observed, with a nonmodified $\mathrm{O}$ adsorption energy but a more negative $\mathrm{C}$ adsorption energy. For the $\mathrm{CoRu}$ case, $\mathrm{Co}_{3}$ and $\mathrm{Co}_{2} \mathrm{Ru}$ three-fold hollow sites are available, the latter mixed site being more stable for $C$ adsorption leading to an energy intermediate between that of the two metals. The situation is different for CoAg, since $\mathrm{C}$ interaction with $\mathrm{Ag}$ is weaker and the best site is $\mathrm{Co}_{3}$, electronically modified by $\mathrm{Ag}$ neighbours. The $\mathrm{C}$ binding energy is hence not intermediate between that of $\mathrm{Co}$ and $\mathrm{Ag}$ (this would be lower in absolute value than for $\mathrm{Co}$ ), but in contrast even more negative than that of Co. Hence both dilute $\mathrm{CoRu}$ and $\mathrm{CoAg}$ bimetallic catalyst are located at the left-hand side of $\mathrm{Co}$ in the diagram, exhibiting a similar theoretical activity compared to the parent $\mathrm{Co}$, but with an enhanced selectivity to the primary amine.

The experimental TOFs at isoconversion (39-43\%) for the direct amination reaction of 1-octanol with $\mathrm{NH}_{3}$ over the $\mathrm{Co}_{98.5} \mathrm{Pt}_{1.5}, \mathrm{Co}_{98.5} \mathrm{Pd}_{1.5}, \mathrm{Co}_{98.5} \mathrm{Ag}_{1.5}$ and $\mathrm{Co}_{98.5} \mathrm{Ru}_{1.5}$ catalysts (Figure 6) were measured by considering the extent of reduction (EOR) and metal dispersion for each catalyst (Supplementary Table 11). Doping with Pt and Pd strongly enhances the TOF over the parent Co catalyst, but at the expense of a large decline of the primary amine (i.e. ocylamine, $\mathrm{OA}$ ) selectivity (Figure 7). The combination of Co with Ru or Ag exerts only a small effect (decrease) on the TOF while the $\mathrm{OA}$ selectivity is maintained in the margins of errors for Ru compared to the parent Co and even significantly increased in the case of Ag doping (see also Supplementary Figures 22-24). Altogether, $\mathrm{Co}_{98.5} \mathrm{Ru}_{1.5}$ and $\mathrm{Co}_{98.5} \mathrm{Ag}_{1.5}$ bimetallic catalysts exert an increase by $8-10 \%$ of the $\mathrm{OA}$ yield compared to the monometallic Co catalyst. These results with $\mathrm{Pt}, \mathrm{Pd}, \mathrm{Ru}$ and $\mathrm{Ag}$ doping of Co validate the predicted behaviour from our computation approach and $\mathrm{Co}_{98.5} \mathrm{Ag}_{1.5}$ appears as a high performance catalyst.

The second case deals with Pd-based alloy. As described above, Pd shows a limited OA selectivity, since C-N coupling has a low barrier. Calculations suggest that a dilute alloy with Ru would benefit from the much better selectivity of $\mathrm{Ru}$. Indeed, the PdRu point is shifted to the low part of Figure $3 \mathrm{~b}$. In good agreement with this prediction, the $\mathrm{Pd}_{98.5} \mathrm{Ru}_{1.5}$ catalyst shows a high OA selectivity versus total amine produced ( $89 \%$, Figure 7 , Supplementary Table 4 , similar to the best value for $\mathrm{Co}$ ). However, the activity is not very high, so that the OA yield remains 4 times smaller than that for the Co catalyst.

The last example concerns alloys based on Ru. Ru shows a peculiar position on the map of Figure 3, exploring the left part of the activity ridge and a zone where selectivity to the primary amine should be high. Dilute alloys with $\mathrm{Pd}$, Ag and $\mathrm{Ni}$ have been considered, since they span various positions on the activity ridge. A diluted alloy with Ni appears more on the right-hand side of the ridge compared to the other alloys, so it is expected to be less selective to the primary amine, which is fully confirmed by the experiments (77\% OA selectivity vs. $87 \%$ for Ru, Figure 7, Supplementary Table 4). In contrast, $\mathrm{Ru}_{98.5} \mathrm{Ag}_{1.5}$ on the left-hand side of the ridge of Figure 3 is highly selective to OA (92\%). The activity however remains markedly smaller than that of Co (6 times lower for the OA yield). 


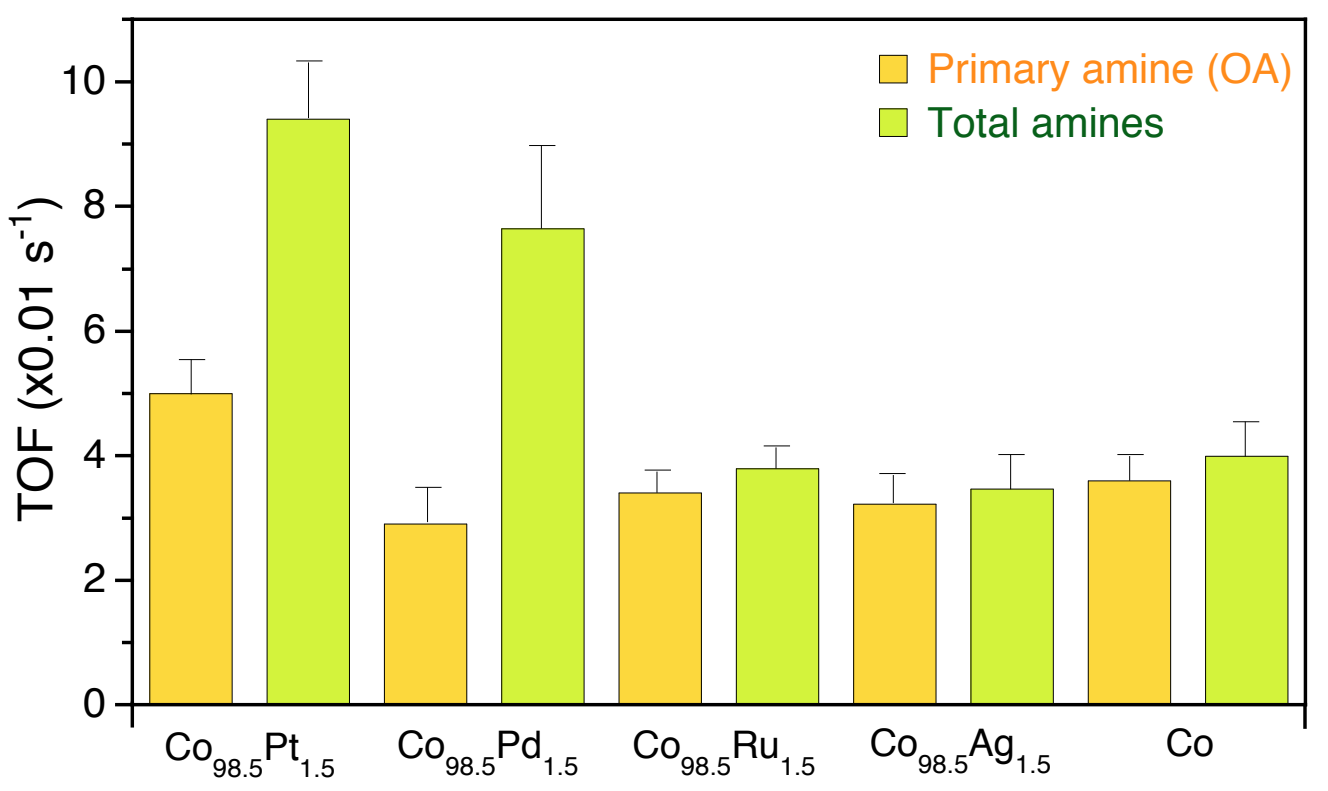

Figure 6. Experimental TOF for amines in the amination of 1-octanol with $\mathrm{NH}_{3}$ on cobalt based bimetallic catalysts. TOF for primary amine ocylamine (orange) and total amine (green) formation is shown over bimetallic $\mathrm{Co}_{98.5} \mathrm{X}_{1.5}$ catalysts $\left(\mathrm{X}=\mathrm{Ru}, \mathrm{Ag}, \mathrm{Pd}\right.$ or Pt). Reaction conditions: $\mathrm{T}=453 \mathrm{~K}, \mathrm{P}=101 \mathrm{kPa}, \mathrm{p}_{\mathrm{OL}}=2.7-16 \mathrm{kPa}, \mathrm{p}_{\mathrm{NH} 3}=18-24 \mathrm{kPa}, \mathrm{p}_{\mathrm{H} 2}=36 \mathrm{kPa}$, $\mathrm{WHSV}_{\mathrm{OL}}=1-15 \mathrm{~h}^{-1}$. The catalysts were pre-reduced at $500{ }^{\circ} \mathrm{C}$ for $1 \mathrm{~h}$ before reaction. The catalysts are based on 5 wt.\%Co over alumina with 1.5 atom $\%$ X prepared by co-impregnation of the Co and $\mathrm{X}$ aqueous precursors. The error bars were measured according to the method described in the Supplementary Information (Catalytic Tests).

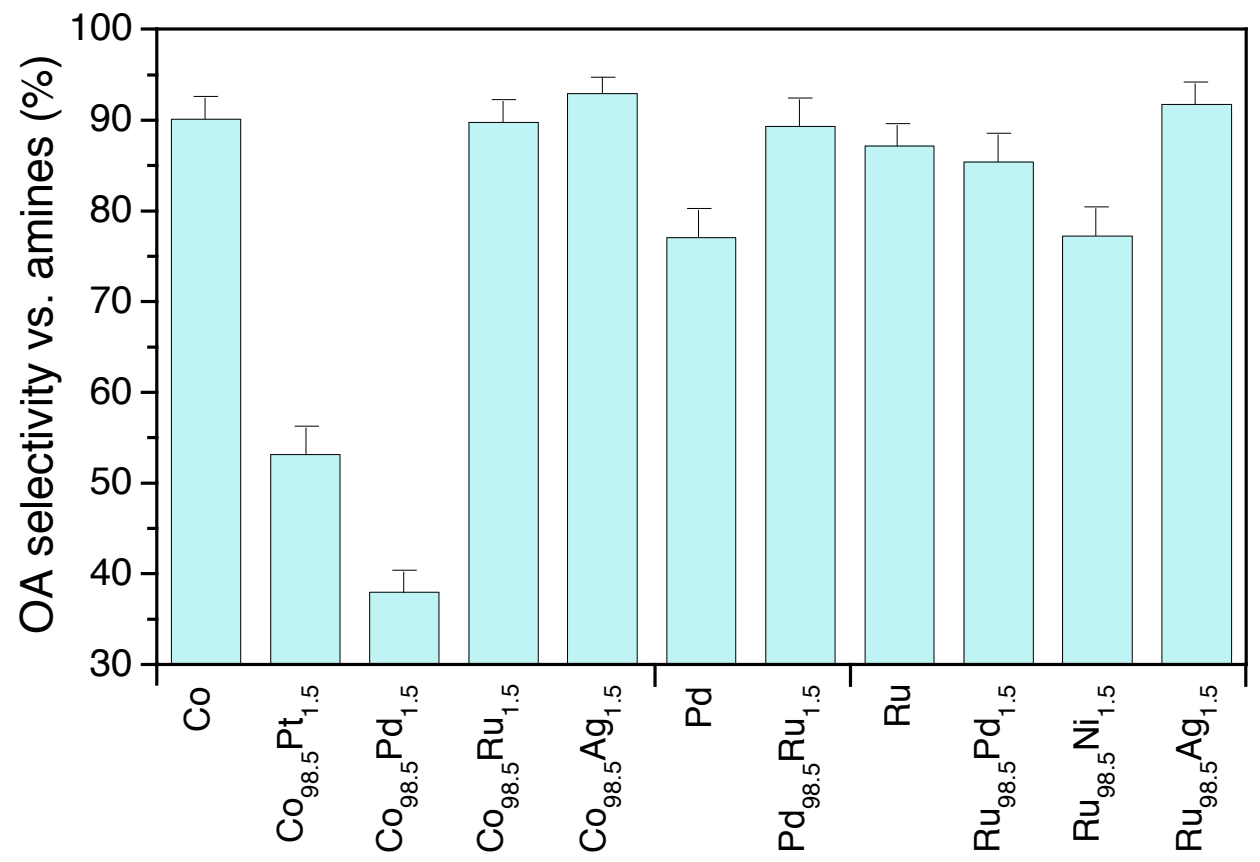

Figure 7 Experimental selectivity to the primary amine ocylamine (OA) versus total amine produced. The considered dilute alloys are compared with the parent metals: $\mathrm{Co}_{98.5} \mathrm{Pt}_{1.5}, \mathrm{Co}_{98.5} \mathrm{Pd}_{1.5}, \mathrm{Co}_{98.5} \mathrm{Ru}_{1.5}$ and $\mathrm{Co}_{98.5} \mathrm{Ag}_{1.5}$ with $\mathrm{Co}$, $\mathrm{Pd}_{98.5} \mathrm{Ru}_{1.5}$ with $\mathrm{Pd}, \mathrm{Ru}_{98.5} \mathrm{Pd}_{1.5}, \mathrm{Ru}_{98.5} \mathrm{Ni}_{1.5}, \mathrm{Ru}_{98.5} \mathrm{Ag}_{1.5}$ with $\mathrm{Ru}$. Reaction conditions are identical to those in Figure 6 . The error bars were measured according to the method described in the Supplementary Information (Catalytic Tests). 


\section{Conclusion}

Linking the catalytic performance with surface properties is a key objective in heterogeneous catalysis. The factors governing the activity and selectivity of metal catalysts for the direct amination of alcohols were assessed by combining first-principle calculations, microkinetic modelling and catalytic experiments. Using simultaneously adsorption-energy and activation-energy scaling relations, the activity and selectivity for metal catalysts could be mapped by using only two descriptors, selected as the adsorption energies of $O$ and $C$ atoms on the catalyst surface. The catalytic activity was mainly controlled by the $\mathrm{O}$ adsorption energy and accordingly the oxophilic nature of the metal catalyst. Two zones of high catalytic activity emerge: one for weakly oxophilic metals (around $\mathrm{Pt}$ ) and a second one for metals with higher $\mathrm{O}$ adsorption energy (around $\mathrm{Ni}$ and $\mathrm{Co}$ ). We show that a major reason for the loss of primary amine selectivity is a surfacemediated C-N bond coupling between two $\mathrm{N}$-containing intermediates: $\mathrm{CH}_{3} \mathrm{NH}$ and $\mathrm{CH}_{2} \mathrm{NH}$. The barrier for this step is low enough to compete with the hydrogenation towards the amine product, and was used as a descriptor for the catalyst selectivity towards the primary amine. The barrier for this unwanted $\mathrm{C}-\mathrm{N}$ formation surface reaction was linearly correlated to the $\mathrm{N}$ adsorption energy on the catalyst, and therefore to $\mathrm{O}$ and $\mathrm{C}$ adsorption energies, hence providing a simple graphical representation of the selectivity. More oxophilic metals exhibit higher $\mathrm{C}-\mathrm{N}$ coupling barriers, and hence a better selectivity towards primary amines. This observation provides a clear explanation why noble metal catalysts $(\mathrm{Pt}, \mathrm{Pd})$ are not selective for primary amine formation.

The descriptors used for the activity/selectivity maps developed for monometallic catalysts were further used to design bimetallic catalysts by computational screening of a large ensemble of dilute bimetallic solids. 76 candidates with potential high activity and selectivity for the reaction were found. From these, three families of dilute bimetallic systems, based on Co, $\mathrm{Pd}$ and $\mathrm{Ru}$ have been tested experimentally. Experiments validate the trends shown in the theoretical activity/selectivity maps. The combination of $\mathrm{Co}$ with $\mathrm{Pt}$ or $\mathrm{Pd}\left(\mathrm{Co}_{98.5} \mathrm{Pt}_{1.5}\right.$ or $\left.\mathrm{Co}_{98.5} \mathrm{Pd}_{1.5}\right)$ may enhance the TOF for 1octanol conversion, but since this enhancement is based on a reduced oxophilic character, this is unfortunately accompanied by a decrease of selectivity towards the primary amine. The combination of Co with Ru or Ag shows a weak effect of the activity, but the selectivity to the primary amine compared to the Co parent catalyst is maintained or even increased for the Ag doping case, resulting in the best catalyst produced in this study $\left(\mathrm{Co}_{98.5} \mathrm{Ag} \mathrm{g}_{1.5}\right)$. $\mathrm{Pd}$ and $\mathrm{Ru}$ based alloys produce highly selective catalysts, but the activity remains moderate. The theoretical methodology described in this paper opens up a route for the rational design of more selective catalysts for direct amination reactions of alcohols and can be extended to other complex reaction networks where selectivity acts as an important bottleneck.

\section{Methods}

Theoretical method and models: All computations were performed by applying plane-wave based density functional theory (DFT) with the Vienna Ab Initio Simulation Package (VASP). ${ }^{48,49}$ The electron ion interaction was described with the projector augmented wave (PAW) method, ${ }^{50,51}$ while the electron exchange and correlation energy was solved within the generalized gradient approximation with the Perdew-Burke-Ernzerhof formalism (PBE). ${ }^{52}$ An energy cut-off of $400 \mathrm{eV}$ was used to ensure accurate energies. The density-dependent $\mathrm{dDsC}$ method was used for the dispersion correction. ${ }^{53}$ The calculated adsorption energy for methanol on $\mathrm{Pt}(111)$ at $1 / 9 \mathrm{ML}$ coverage $(0.51 \mathrm{eV})$ agrees well with single-crystal adsorption calorimetry. ${ }^{54}$

Microkinetic modelling method: For mapping the catalytic activity, we used the descriptor-based microkinetic software 
package CatMAP developed by Medford et al., ${ }^{46}$ which is based on scaling and BEP relations. However, some essential modifications were introduced into the original software to obtain correct steady-state coverages, since the default approach to solve the microkinetic model in CatMAP was found to yield incorrect zero activity for some descriptor combinations (more details could be found in Supplementary Methods).

Experimental methods: A series of monometallic ( $\mathrm{Ni}, \mathrm{Co}, \mathrm{Pd}, \mathrm{Pt}, \mathrm{Ru})$ and bimetallic $\left(\mathrm{Co}_{98.5} \mathrm{Pt}_{1.5}, \mathrm{Co}_{98.5} \mathrm{Pd}_{1.5}, \mathrm{Co}_{98.5} \mathrm{Ru}_{1.5}\right.$, $\mathrm{Co}_{95.5} \mathrm{Ru}_{4.5}, \mathrm{Co}_{98.5} \mathrm{Ag}_{1.5}, \mathrm{Ni}_{98.5} \mathrm{Ru}_{1.5}, \mathrm{Pd}_{98.5} \mathrm{Ru}_{1.5}, \mathrm{Ru}_{98.5} \mathrm{Pd}_{1.5}, \mathrm{Ru}_{98.5} \mathrm{Ni}_{1.5}, \mathrm{Ru}_{98.5} \mathrm{Ag}_{1.5}$ ) catalysts based on $5 \mathrm{wt} \%$ for the main metal and a nominal molar composition of $1.5 \mathrm{~mol} \%$ for the second metal were prepared by incipient wetness impregnation using an aqueous solution of metal nitrates over $\gamma-\mathrm{Al}_{2} \mathrm{O}_{3}$ (see details in Supplementary Methods and Supplementary Figures 19-21 and 26-30). The catalysts were characterized in detail by inductively coupled plasma optical emission spectrometry, X-ray diffraction, HR-TEM, STEM-EDX-SDD and $\mathrm{H}_{2}$-Temperature Programmed Reduction $\left(\mathrm{H}_{2}\right.$-TPR) (see details in Supplementary Table 11) and were further tested in the gas-phase amination of 1-octanol with $\mathrm{NH}_{3}$ in a fixed-bed reactor at $453 \mathrm{~K}$ and $101 \mathrm{kPa}$ total pressure using a feed flowrate of 0.6-9.0 $\mathrm{mL} \cdot \mathrm{h}^{-1}$ and a catalyst weight of $500 \mathrm{mg}$. The partial pressure of 1-octanol, $\mathrm{NH}_{3}$ and $\mathrm{H}_{2}$ were kept in the range 2.7-16 kPa, 18-24 kPa and $36 \mathrm{kPa}$, respectively, while balance $\mathrm{N}_{2}$ was used as carrier. Notably, a high $\mathrm{H}_{2}$ partial pressure was employed to discourage deactivation by coke formation and to ensure the measurement of intrinsic conversion and selectivity. ${ }^{55,56,57}$ Besides, dedicated tests for $12 \mathrm{~h}$ on stream for the bimetallic $\mathrm{Co}$ and monometallic Ni catalysts revealed no apparent change of the catalytic activity, pointing out a lack of catalyst deactivation by coking. The catalytic tests were conducted at least three times on consecutive experiments with a time on stream of $3 \mathrm{~h}$ for each test. The kinetic curves were measured by changing the weight-hourly-space-velocity (WHSV) in a random fashion. Preliminary tests confirmed the absence of external mass transfer effects on the catalytic activity. Before each test, the catalysts were reduced in situ at different temperatures according to their corresponding $\mathrm{H}_{2}$-TPR profiles. The recovered liquid samples were analysed offline using a GC (Agilent 7890A GC) equipped with a $30 \mathrm{~m} \times 0.32 \mathrm{~mm} \times 0.25 \mu \mathrm{m}$ Zebron HP-5 column with 5 wt. \% phenyl groups and a FID detector. The column was temperature-programmed with a $3 \mathrm{~K} \mathrm{~min}^{-1}$ initial ramp from $353 \mathrm{~K}$ to $373 \mathrm{~K}$ followed by a $50 \mathrm{~K} \cdot \mathrm{min}^{-1}$ ramp to $573 \mathrm{~K}$ and holding this temperature for $3 \mathrm{~min}$.

Data availability: The data that support the plots within this paper and other findings of this study are available from the corresponding author upon reasonable request.

Acknowledgment: This work received granted access to the HPC resources of CINES and IDRIS under the allocation 2015-080609 made by GENCI. It also benefited from the computational resources of the PSMN. Financial support was provided by the ANR grant SHAPES (13-CDII-0004-06). The authors would like to express their gratitude to Dr. Eric Leroy from ICMPE-CMTR (UMR 7182 CNRS) for measuring the STEM-EDS-SDD cartographies.

Author contributions: TW and MS conducted the DFT calculations and micro-kinetics simulations, KW, LF, SP and JI did the experiments, and PS, CM and MPT designed the study and wrote the paper.

Competing interests: The authors declare no competing interests.

\section{Additional information}

Supplementary information is available for this paper at http://xxxxxxx. 


\section{References}

1 Brown, B. R. The organic chemistry of aliphatic nitrogen compounds, (Oxford University Press, New York, 1994).

2 Rappoport, Z. The chemistry of anilines, (Wiley, Chichester, 2007).

3 Lawrence, S. A. Amines : synthesis, properties and applications, (Cambridge University Press, Cambridge, 2004).

4 Pera-Titus, M. \& Shi, F. Catalytic amination of biomass-based alcohols, ChemSusChem. 7, 1-4 (2014).

5 Guillena, G., Ramón, D. J. \& Yus, M. Hydrogen autotransfer in the $n$-alkylation of amines and related compounds using alcohols and amines as electrophiles. Chem. Rev. 110, 1611-1641 (2009).

6 Dobereiner, G. E. \& Crabtree, R. H. Dehydrogenation as a substrate-activating strategy in homogeneous transitionmetal catalysis. Chem. Rev. 110, 681-703 (2010).

7 Saidi, O.; Blacker, A. J., Farah, M. M.; Marsden, S. P. \& Williams, J. M. J. Selective amine cross-coupling using Iridium-catalyzed "borrowing hydrogen" methodology. Angew. Chem. Int. Ed. 48, 7375-7378 (2009).

8 Klinkenberg, J. L. \& Hartwig, J. F. Catalytic organometallic reactions of ammonia. Angew. Chem. Int. Ed. 50, 86-95 (2011).

9 Gunanathan, C. \& Milstein, D. Applications of acceptorless dehydrogenation and related transformations in chemical synthesis. Science 341, 1229712 (2013).

10 Imm, S., Bahn, S., Neubert, L., Neumann, H. \& Beller, M. An efficient and general synthesis of primary amines by ruthenium-catalyzed amination of secondary alcohols with ammonia. Angew. Chem. Int. Ed. 49, 8126-8129 (2010).

11 Kim, J. W., Yamaguchi, K. \& Mizuno, N. Heterogeneously catalyzed selective N-alkylation of aromatic and heteroaromatic amines with alcohols by a supported ruthenium hydroxide. J. Catal. 263, 205-208 (2009).

12 Shimizu, K., Nishimura, M. \& Satsuma, A. $y$-alumina-supported silver cluster for $n$-benzylation of anilines with alcohols. ChemCatChem 1, 497-503 (2009).

13 Cui, X., Zhang, Y., Shi, F. \& Deng, Y. Organic ligand-free alkylation of amines, carboxamides, sulfonamides, and ketones by using alcohols catalyzed by heterogeneous Ag/Mo oxides. Chem. Eur. J. 17, 1021-1028 (2011).

$14 \mathrm{He}$, L. et al. Efficient and clean gold-catalyzed one-pot selective n-alkylation of amines with alcohols. Chem. Eur. J. 16, 13965-13969 (2010).

$15 \mathrm{He}, \mathrm{W}$. et al. Pt-Sn/Y-Al $\mathrm{O}_{3}$-catalyzed highly efficient direct synthesis of secondary and tertiary amines and imines. Chem. Eur. J. 17, 13308-13317 (2011).

16 Zhang, Y., Qi, X., Cui, X., Shi, F. \& Deng, Y. Palladium catalyzed N-alkylation of amines with alcohols. Tetrahedron Lett. 52, 1334-1338 (2011).

17 Corma, A., Ródenas, T. \& Sabater, M. J. A bifunctional Pd/MgO solid catalyst for the one-pot selective nmonoalkylation of amines with alcohols. Chem. Eur. J. 16, 254-260 (2010).

18 Kwon, M. S. et al. One-pot synthesis of imines and secondary amines by Pd-catalyzed coupling of benzyl alcohols and primary amines. J. Org. Chem. 74, 2877-2879 (2009).

19 Shimizu, K-I., Kon, K., Onodera, W., Yamazaki, H. \& Kondo, J. N. Heterogeneous Ni catalyst for direct synthesis of primary amines from alcohols and ammonia. ACS Catal. 3, 112-117 (2013).

20 Shimizu, K-I., Imaiida, N., Kon, K., Siddiki, S. M. A. H. \& Satsuma, A. Heterogeneous Ni catalysts for $n$-alkylation of amines with alcohols. ACS Catal. 3, 998-1005 (2013).

21 Cho, J. H., Park, J. H., Chang, T. S., Kim, J. E. \& Shin, C. H. Reductive amination of 2-propanol to monoisopropylamine over $\mathrm{Ni} / \mathrm{Y}-\mathrm{Al}_{2} \mathrm{O}_{3}$ catalysts. Catal. Lett. 143, 1319-1327 (2013). 
22 Shimizu, K-I. Heterogeneous catalysis for the direct synthesis of chemicals by borrowing hydrogen methodology. Catal. Sci. Technol. 5, 1412-1427 (2015).

23 Tomer, A., Yan, Z., Ponchel, A. \& Pera-Titus, M. Mixed oxides supported low-nickel formulations for the direct amination of aliphatic alcohols with ammonia. J. Catal. 356, 133-146 (2017).

24 Tomer, A. et al. Cyclodextrin-assisted synthesis of $\mathrm{Ni} / \mathrm{Al}_{2} \mathrm{O}_{3}$ catalysts for direct amination of fatty alcohols, J. Catal. 356, 459-466 (2017).

25 Baiker, A. \& Richarz, W. Catalytic amination of long chain aliphatic alcohols. Ind. Eng. Chem. Prod. Res. Dev. 16, 261-266 (1977).

26 Santoro, F., Psaro, R., Ravasio, N. \& Zaccheria, F. Reductive amination of ketones or amination of alcohols over heterogeneous Cu catalysts: matching the catalyst support with the n-alkylating agent. ChemCatChem 4, 1249-1254 (2012).

27 Cho, J. H., Park, J. H., Chang, T. S., Seo, G. \& Shin, C. H. Reductive amination of 2-propanol to monoisopropylamine over $\mathrm{Co} / \mathrm{y}-\mathrm{Al}_{2} \mathrm{O}_{3}$ catalysts. Appl. Catal. A: Gen. 417-418, 313-319 (2012).

28 Rausch, A. K., Stehen, E. \& Roessner, F. New aspects for heterogeneous cobalt-catalyzed hydroamination of ethanol. J. Catal. 253, 111-118 (2008).

29 Baiker, A. \& Kijenski, J. Catalytic synthesis of higher aliphatic amines from the corresponding alcohols. Catal. Rev. Sci. Eng. 27, 653-697 (1985).

30 Kimura, H. \& Taniguchi, H. Targeting quantitative synthesis for the one-step amination of fatty alcohols and dimethylamine. Appl. Catal. A: Gen. 287, 191-196 (2015).

31 Cui, X., Dai, X., Deng, Y. \& Shi, F. Development of a general non-noble metal catalyst for the benign amination of alcohols with amines and ammonia. Chem. Eur. J. 19, 3665 (2013).

32 Van Santen, R. A. \& Neurock, M. Molecular Heterogeneous Catalysis: A Conceptual and Computational Approach, (Wiley-VCH, Weinheim, 2006).

33 Nøskov, J. K., Studt, F., Abild-Pedersen, F. \& Bligaard, T. Fundamental Concepts in Heterogeneous Catalysis, (John Wiley \& Sons, Inc, Hoboken, New Jersey, 2014).

34 Dumon, A. S. et al. Direct n-octanol amination by ammonia on supported Ni and Pd catalysts: activity is enhanced by "spectator" ammonia adsorbates. Catal. Sci. Technol. 22, 611 (2018).

35 Baiker, A., Caprez, W. \& Holstein, W. L. Catalytic amination of aliphatic alcohols in the gas an liquid phases: kinetics and reaction pathway. Ind. Eng. Chem. Prod. Res. Dev. 22, 217 (2017).

36 Ogata, Y. \& Kawasaki, A. Kinetics of the condensation of acetaldehyde with ammonia. Tetrahedron, 20, 855-860 (1964).

37 Tamura, M. \& Tomishige, K. Redox properties of $\mathrm{CeO}_{2}$ at low temperature: the direct synthesis of imines from alcohol and amine. Angew. Chem. Int. Ed. 54, 864-867 (2015).

38 Ruiz, D. et al. Direct amination of dodecanol with $\mathrm{NH}_{3}$ over heterogeneous catalysts. Catalyst screening and kinetic modelling. Chem. Eng. J. 307, 739-749 (2017).

39 Abild-Pedersen, F. et al. Scaling properties of adsorption energies for hydrogen-containing molecules on transitionmetal surfaces. Phys. Rev. Lett. 99, 016105 (2007).

40 Calle-Vallejo, F., Loffreda, D., Koper, M. T. M. \& Sautet, P. Introducing structural sensitivity into scaling relations between adsorption energies by means of coordination numbers. Nat. Chem. 7, 403-410 (2015). 
41 Van Santen, R. A., Neurock, M. \& Shetty, S. G. Reactivity Theory of transition-metal surfaces: a Brønsted-EvansPolanyi linear activation energy-free-energy analysis. Chem. Rev. 110, 2005-2048 (2010).

42 Liu, Z. P. \& Hu, P. General trends in CO dissociation on transition metal surfaces. J. Chem. Phys. 114, 8244-8247 (2011).

43 Wang, S., Vorotnikov, V., Sutton, J. E. \& Vlachos, D. G. Brønsted-Evans-Polanyi and transition state scaling relations of furan derivatives on $\mathrm{Pd}(111)$ and their relation to those of small molecules. ACS Catal. 4, 604-612 (2014).

44 Honkala, K. et al. Ammonia synthesis from first-principles calculations. Science 307, 555-558 (2005).

45 Studt, F. et al. Identification of non-precious metal alloy catalysts for selective hydrogenation of acetylene. Science 320, 1320-1322 (2008).

46 Medford, A. J. et al. CatMAP: a software package for descriptor-based microkinetic mapping of catalytic trends. Catal. Lett. 145, 794-807 (2015).

47 Gomez, S., Peters, J. A. \& Maschmeyer, T. The reductive amination of aldehydes and ketones and the hydrogenation of nitriles: mechanistic aspects and selectivity control. Adv. Synth. Catal. 344, 1037-1057 (2002).

48 Kresse, G. \& Furthmüller, J. Efficiency of ab-initio total energy calculations for metals and semiconductors using a plane-wave basis set. Comput. Mater. Sci. 6, 15-50 (1996).

49 Kresse, G. \& Furthmüller, J. Efficient iterative schemes for ab initio total-energy calculations using a plane-wave basis set. Phys. Rev. B 54, 11169-11186 (1996).

50 Blochl, P. E. Projector augmented-wave method. Phys. Rev. B 50, 17953-17979 (1994).

51 Kresse, G. From ultrasoft pseudopotentials to the projector augmented-wave method. Phys. Rev. B 59, 1758-1775 (1999).

52 Perdew, J. P., Burke, K. \& Ernzerhof, M. Generalized gradient approximation made simple. Phys. Rev. Lett. 77, 3865-3868 (1996).

53 Steinmann, S. N. \& Corminboeuf, C. Comprehensive benchmarking of a density-dependent dispersion correction. J. Chem. Theory Comput. 7, 3567-3577 (2011).

54 Silbaugh, T. L. \& Campbell, C. T. Energies of formation reactions measured for adsorbates on late transition metal surfaces. J. Phys. Chem. C 120, 25161-25172 (2016).

55 Baiker, A., Monti, D. \& Fan, Y. S. Deactivation of copper, nickel, and cobalt catalysts by interaction with aliphatic amines. J. Catal. 88, 81-88 (1984).

56 Baiker, A. The role of hydrogen in the catalytic amination of alcohols and the disproportionate of amines. Stud. Surf. Sci. Catal. 41, 283-290 (1988).

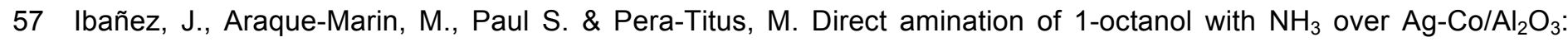
Promoting effect of the $\mathrm{H}_{2}$ pressure on the reaction rate. Chem. Eng. J. 358, 1620-1630 (2019). 